UDK 543.51

\title{
IDENTIFICATION OF METHYL TERT-BUTYL ETHER IN HUMAN BLOOD WITH CHROMATOGRAPHY-MASS-SPECTROMETRIC METHOD
}

\section{T.S. Ulanova, T.V. Nurislamova}

Federal Budget Scientific Institution "Federal Scientific Center for Medical and Preventive Health Risk Management Technologies”, Russian Federation, Perm, 82 Monastyrskaya st., 614045

\begin{abstract}
This article details the applying of GC-MS for accurate identification and study the fragmentation of ionized molecules of methyl tert-butyl ether in human blood. Basing on the reception of mass spectrum of ions of methyl tert-butyl ether the structure, molecular weight, elemental composition of a molecule of methyl tert-butyl ether are defined. The characteristic ions (primary and confirming ions) of methyl tert-butyl ether are detected and the chromatographic retention time is determined.

In the process of performing of identification of methyl tret-butyl ether in a blood sample on the mass spectrogram the peak is set which is the result of overlap of several individual peaks of the compounds-isomers with the identical retention times: 2- methylpentane, methyl tert-butyl ether and 3-methyl pentane. To eliminate low resolution in the studies two consecutive capillary columns were used.

Key words: methyl tert-butyl ether, chromatographic-mass-spectrometric method, characteristic ions, massspectrum, mass-selective detector.
\end{abstract}

In order to achieve reliable identification in the evaluation of the adverse effects of the environmental impact on public health, researchers use the results of the studies of the biological environment of the population conducted in the framework of a systematic biomonitoring. High requirements to the qualities of the studies create a need to validate and reliably identify the contaminants registered in the biological environment $[3,7]$. In the context of a comprehensive, multi-component load of the habitat formed by emissions of the chemical, oil-refining plants, transport, etc., in biomonitoring, the issue of reliable and accurate identification of defined chemical compounds in the fact of macroamounts of the biological material of complex composition of the matrix of the biological environment is of particular relevance. To achieve reliable identification, current analytical physico-chemical studies use the method of gas chromatography-mass spectrometry (CMS) [6]. In practical studies, CMS identification of individual contaminants in the biological media can be carried out with the help of a computer library search. Here the ability to identify is determined primarily by the search algorithm and the quality and size of the libraries that usually have thousands of mass spectra [6].

(C) Ulanova T.S., Nurislamova T.V., 2014

Ulanova Tatyana Sergeevna - DSc, Head of Analytical Chemistry Department (e-mail: ula-nova@fcrisk.ru; ph: +7 (342)-233-10-37).

Nurislamova Tatyana Valentinovna - DSc, Head of Gas Chromatography Laboratory (e-mail: Nuris-lamova@fcrisk.ru; ph: +7 (342)-236-32-64). 
In real conditions, the issue is complicated by the fact that impact of the matrix of biological media, the interfering effect of related components, and the instability factors of column background twist the results of the mass spectra, and their reliable interpretation is difficult [6].

The purpose of the research is to develop CMS identification for the determination of methyl-tret-butyl-ether (MTBE) in the blood by the method of library search and comparison by the standard compound.

Materials and methods. The research was carried out by the specialists of the Chemical Analytical Department of the Federal Budget Scientific Institution "Federal Scientific Center for Medical and Preventive Health Risk Management Technologies The object of the research was a biological medium (blood), standard solutions of methyl-tret-butyl-ether, mass chromatograms, and mass spectra of methyl-tret-butyl-ether.

The identification was carried out with the use of "gas chromatography - mass spectrometry" (GC-MS). Chromatographic separation was conducted on an Agilent 7890A gas chromatograph with a mass selective detector and a capillary column 5975S HP-5MS $30 \mathrm{~m}$. $0.250 \mathrm{~mm} \cdot 0.25 \mu \mathrm{m}$. Ionization of MTBE gas molecules was performed by electron impact [2]. The search for characteristic methyl-tret-butyl-ether ions was done with the help of the database of the mass spectral data NIST 08.L library.

Results and discussion. The identification was performed by comparing the mass spectrum of the analyzed compound with the mass spectrum of a standard sample of MTBE with the appropriate databases and computer library search NIST.08L. The results of the identification of the standard sample of MTBE in the mass spectra allowed establishing a chemical composition; main and supporting ions of MTBE; retention time of MTBE; and a chemical structure of MTBE. Chromatogram for total ion current of a standard MTBE sample is shown in Fig. 1.

Evaluation of the similarity of the reference and study spectrograms showed the identity of the mass spectrum of the MTBE standard (upper part of Fig. 2) and its library spectrum (lower part of Fig. 2).

For the studied component, we determined integral molecular features which include molecular weight, the total elemental composition, chemical structural formula, and mass spectra. 
To determine molecular weight and elemental composition of the test compound using mass spectrometry, we set the molecular ion peak and measured the mass to charge ratio. According to the results of the library search, we determined the elemental composition of methyl-tert-butyl-ether (2-methyl-2-methoxypropan) corresponding to the formula $\mathrm{C}_{5} \mathrm{H}_{12} \mathrm{O}$.

Comparison of the mass spectra of the standard sample with the MTBE spectra added to the mass spectral data library NIST 08.L allowed to determine its characteristic ions (primary and confirmatory). Main (maximum) peak in the mass spectrum corresponds to the characteristic ion with the mass of $\mathrm{m} / \mathrm{z} 73.0$, the mass of the confirming ion is $\mathrm{m} / \mathrm{z} 57,41$.

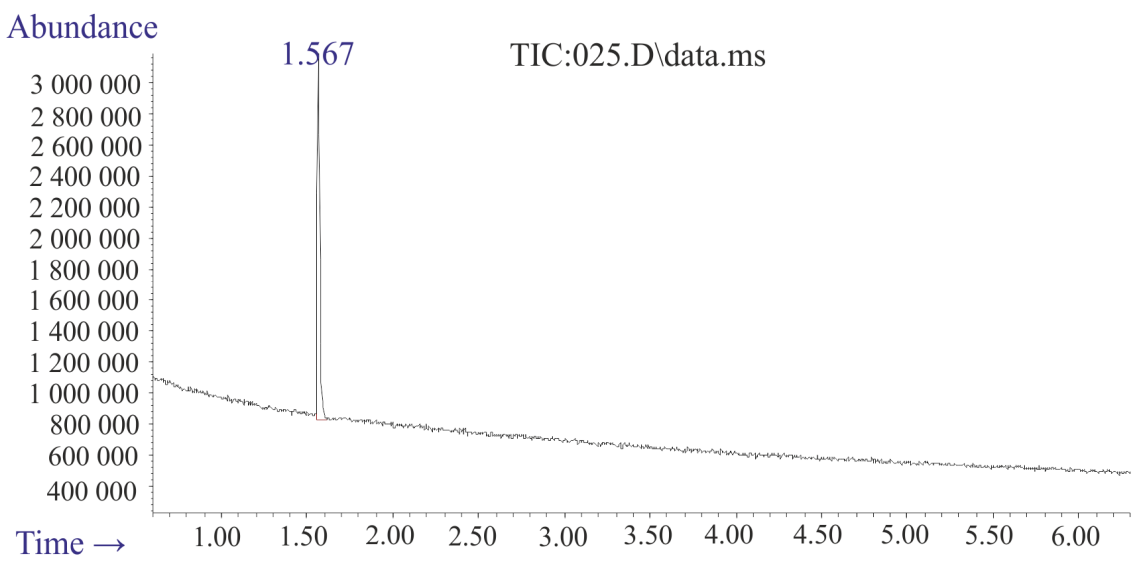

Fig. 1 Chromatogram on the total ion current of the standard MTBE sample (retention time is 1.57 minutes)

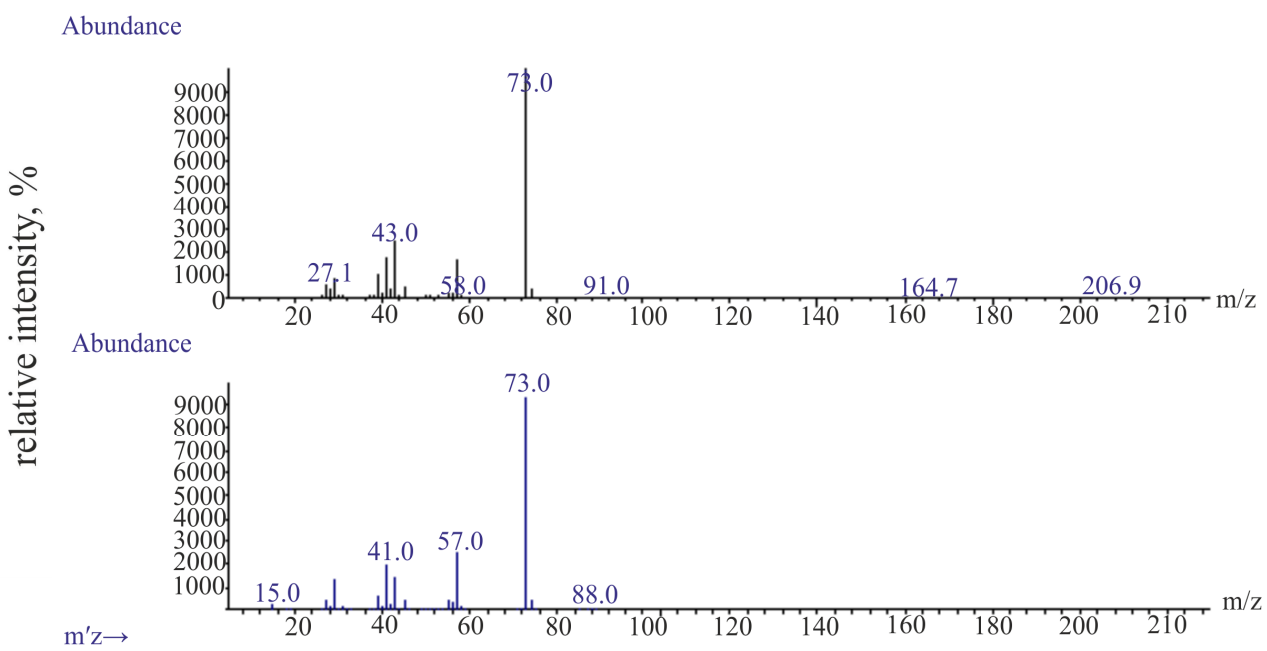

Fig. 2 Mass-spectrogram comparison of the mass spectrum of the MTBE standard and a library spectrum based on characteristic ions $(\mathrm{m} / \mathrm{z} 73,57,41)$ 
The results of the probabilistic search in terms of the quality of matches in the study of standard MTBE samples showed that its mass spectra coincided with the library mass spectra with the value of the similarity factor of more than $90 \%$ at the coincidence of retention time.

MTBE Identification in the blood sample. During the studies, we isolated methyl-tertbutyl-ether from the biological matrix (blood) by creating a headspace in the closed volume and performed a gas chromatographic analysis. [1] When analyzing the headspace of MTBE with the help of GC-MS, a sample was injected into a $30 \mathrm{~m}$ long capillary column of Agilent 7890A gas chromatograph with a mass selective detector 5975S. To achieve reproducibility of mass spectra, ionization of MTBE molecules was carried out in the gas phase by electron impact [4]. Fragment chromatogram for total ion current of the blood sample is shown in Fig. 3.

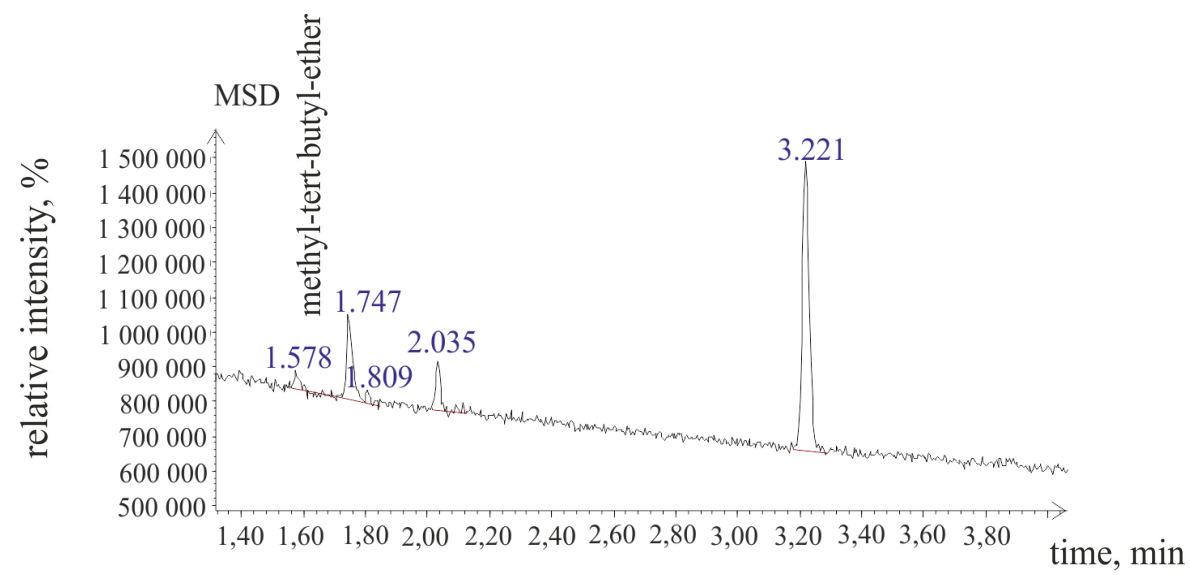

Fig. 3. Fragment chromatogram containing MTBE (retention time is $1.57 \mathrm{~min}$ ), for the total ion current

Mass chromatogram was built on total ion current and characteristic MTBE ions $(\mathrm{m} / \mathrm{z}$ $73.1 ; 57 ; 41)$. Application of capillary gas chromatography in combination with mass spectrometer (GC-MS) allowed for the registration of the chromatogram of a blood sample, which was then reconstructed using the characteristic ions. Scan test of a blood sample across the mass range allowed for the identification of 10 mass spectra of organic compounds: propane, 2-methoxy-2-methyl (methyl-tert-butyl-ether), benzene, toluene, 1,3,5-cycloheptatrien, benzaldehyde, phenol 2-methyl, benzyl alcohol, butyl 2-methyl-propyl-ether, 1,2- benzene dicarboxylic acid, dibutyl phthalate, butyl 4-chlorophenyl ether of phthalic acid with a probability of $78-94 \%$ overlap.

Next stage of the research was to carry out a unique identification of MTBE based on retention parameters (determined by the calibration solutions) and by comparing the 
characteristic ions of the mass spectra with library spectra. To build a mass chromatogram, we used peak intensities of ions from the recorded mass spectrum, and then constructed a graph. Reconstructed mass chromatogram for the characteristic ions of MTBE is shown in Fig. 4 According to the retention time of MTBE, the maxima in mass chromatograms for the entire characteristic ion mass $(\mathrm{m} / \mathrm{z} 73,57$ and 41$)$ in the intense peak spectrum correspond to this compound, confirming the presence of MTBE in the blood.

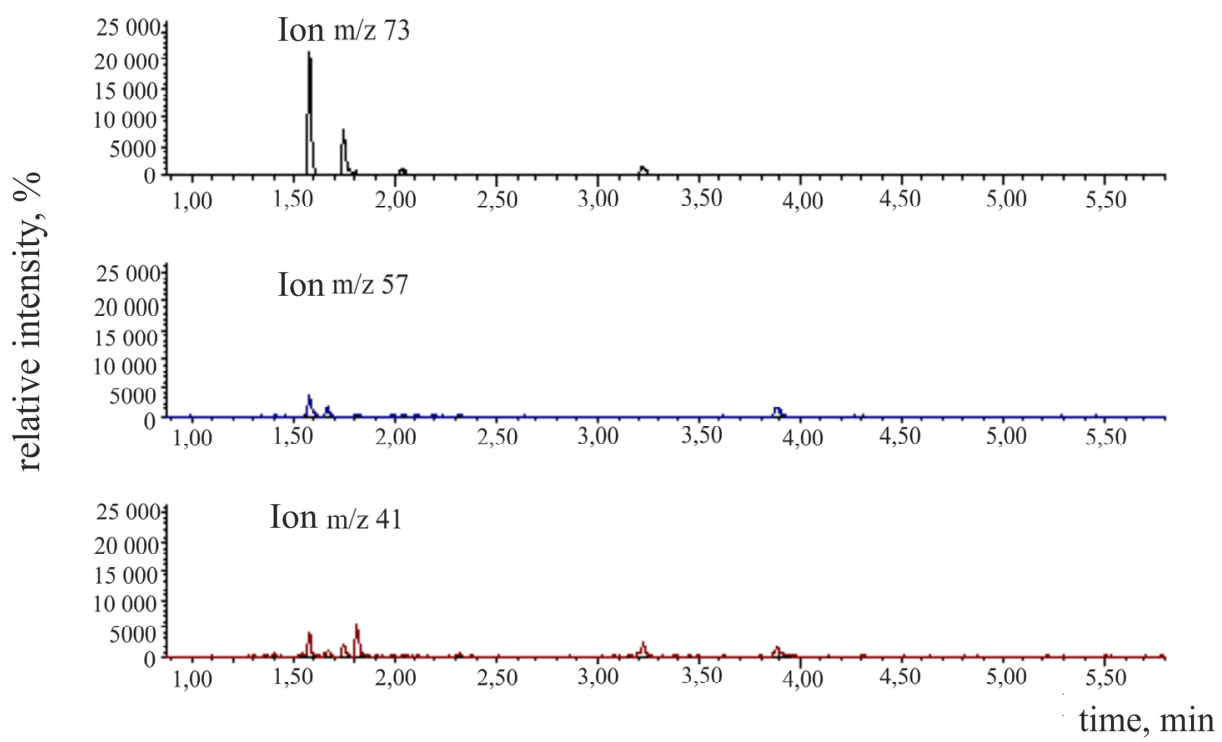

Figr. 4. Mass-chromatogram that correspond to the chromatographic peak of MTBE (characteristic ions $\mathrm{m} / \mathrm{z} 73.57$ and 41 , retention time $-1.57 \mathrm{~min}$ )

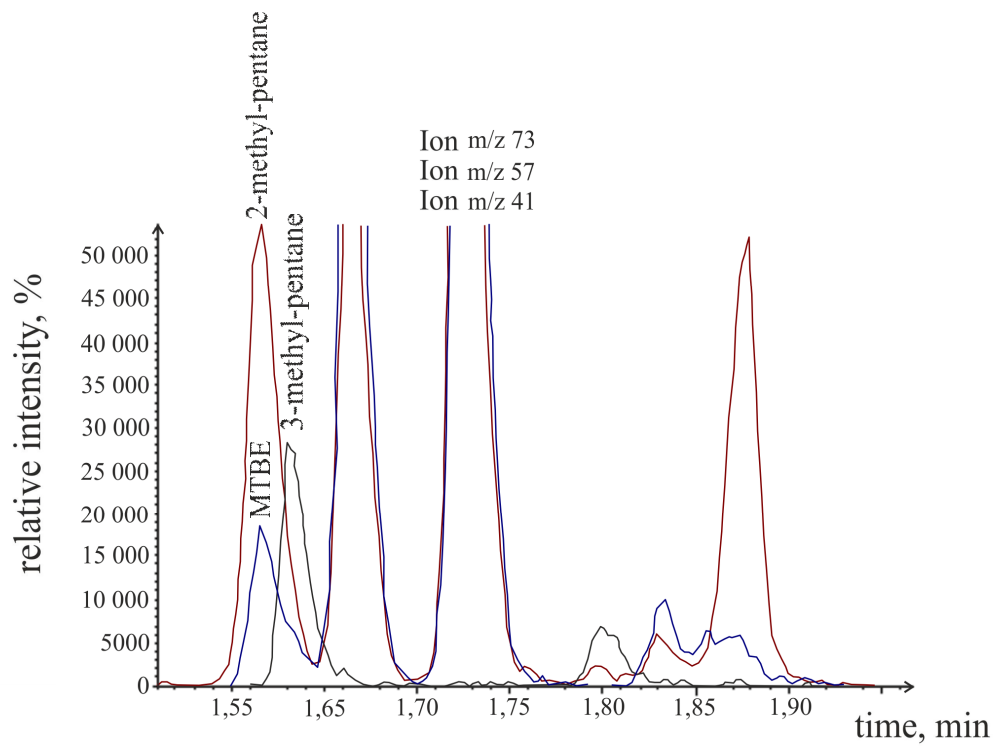

Fig. 5. Mass chromatogram of a blood sample that contain organic compounds: 2-methylpentane, methyl tert-butyl ether and 3-methyl-pentane 
The presence of a mass chromatogram peak of a well-defined mass of $\mathrm{m} / \mathrm{z} 73$ and a retention time of 1.57 min for the studied compounds is a strong evidence of its presence in the blood sample.

During the identification process on the mass chromatogram (see Fig. 5), an ion peak overlap corresponding with the organic compounds was found: 2-methylpentane, methyl-tretbutyl-ether, and 3-metilpentan

The presence of unseparated peaks on a mass chromatogram (see. Fig. 5) is one of the problems encountered during the identification and quantitative analysis of real blood samples [5]. The question about the purity of the peak and the establishment of its uniformity is particularly relevant in the determination of low concentrations of organic compounds in the samples of complex composition, since an overlayp of the peaks of the determined analyte and other compounds will be detected as a single component leading to incorrect results analysis. The analysis of the time dependence of the intensity of the current for individual ions within the distorted peak showed that the times corresponding to the maxima of the ion current of the methylpentan-2 ions (retention time - $1.567 \mathrm{~min}$ ), methyl-tert-butyl ether (retention time - $1.575 \mathrm{~min}$ ) and 3-methyl -pentane (retention time $-1.615 \mathrm{~min}$ ) do not coincide. This confirms that the discussed peak is formed by more than one component.

Since the retention times of the three components constituting a peak are not the same, the mass spectra of the front (1.567 min), medium (1.575) and rear (1.615) of the peak yield clean mass spectrum of each component - 2-methylpentane, methyl-tert-butyl-ether and 3methyl-pentane.

Decoding of the mass spectrum of methyl-tert-butyl-ether was carried out on the retention parameters and by comparing the characteristic ions of mass spectra with the library spectra (see Fig. 6). 


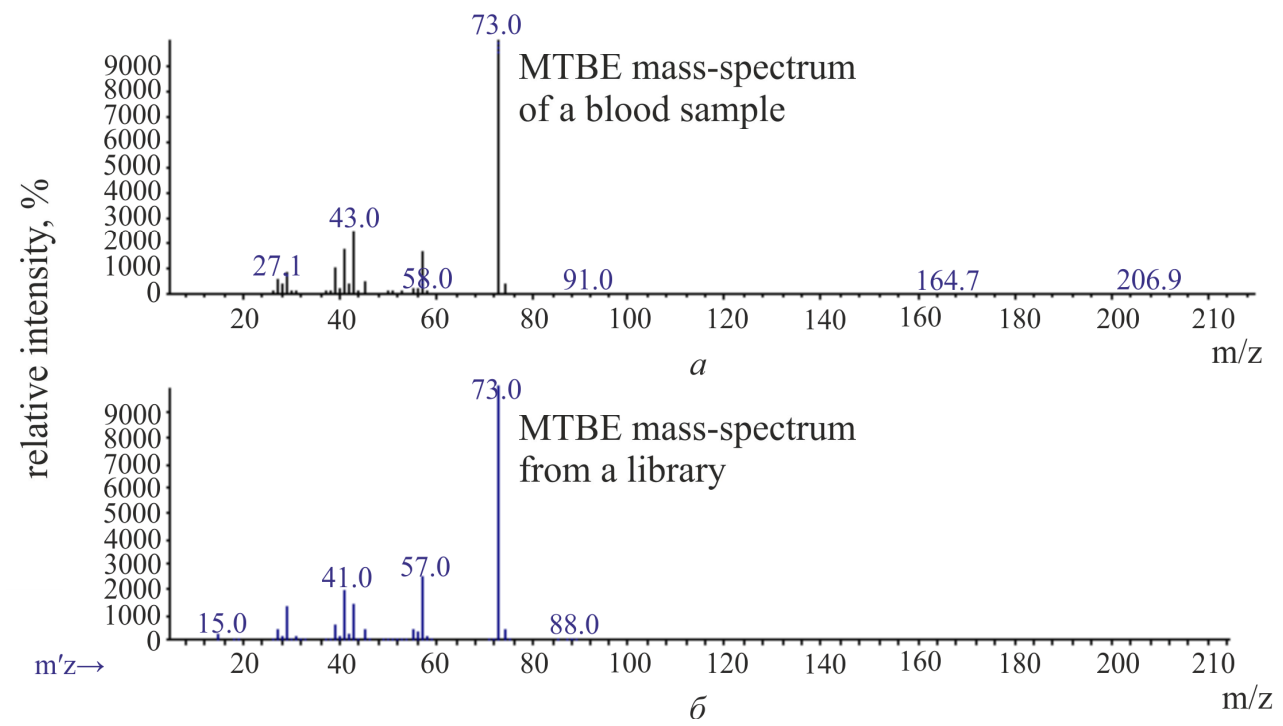

Fig. 6. MTBE mass-spectrum (a) иand its comparison with the library mass-spectrum $(b)$ based on characteristic ions ( $\mathrm{m} / \mathrm{z}$ main 73 , confirming $\mathrm{m} / \mathrm{z} 57,41)$

Analysis of the reference and test spectrogram shows equivalence of the mass spectrum of methyl-tert-butyl-ether component in the blood sample (upper part of Fig. 6) and its library spectrum (bottom part of Fig. 6).

A mass chromatogram (see. Fig. 6) of the test sample of blood peak with a retention time in the range of $1.567-1.615 \mathrm{~min}$ is the result of an overlap of several individual peaks of isomer compounds with identical retention times, so to separate the isomers of saturated hydrocarbons (2-methyl-pentane, 3-methylpentane) and methyl-tert-butyl-ether, it is necessary to select new conditions for chromatographic separation. To do that, in the course of the research we substantiated the use of a non-polar column connected in series with the working liquid phase based on the DB-624 polymethylsiloxane $60 \mathrm{~m} \times 0,32 \mathrm{~mm} \times 1,8 \mu \mathrm{m}$ and polar polyethylene glycol, high-resolution and low detection limit of HP-January $30 \mathrm{~m} \times$ $0.32 \mathrm{~mm} \times 0,25 \mu \mathrm{m}$. Under these conditions, the chromatogram has no peak that corresponds to the isomers of 2-methylpentane and 3-methylpentane, and the retention time of methyltert-butyl-ether is $11.3 \mathrm{~min}$. The use of different columns makes it possible to change the retention indices of the same substances in the analysis to determine the precise identification of compounds present in a biological sample analyzed.

Completed studies were used in the development of a method to determine methyltert-butyl-ether in the blood to assess the impact of this compound on human health, to 
conduct risk assessment, and carry out a research in the framework of public health monitoring.

\section{References}

1. Vittenberg A.G. Parofaznyj gazohromatograficheskij analiz [Head space gaschromatographic analysis]. V sb. «Pamjati B.V.Ioffe», St. Petersburg: NII Himii SPbGU, 1998, pp. 7-69.

2. Vul'fson N.S., Zaikin V.G., Mikaja A.I. Mass-spektrometrija organicheskih soedinenij [Mass spectrometry of organic compounds]. Moscow: Himija. 1986, 312 p.

3. Zajceva N.V., Maj I.V., Klejn S.V. K voprosu ustanovlenija i dokazatel'stva vreda zdorov'ju naselenija pri vyjavlenii nepriemlemogo riska, obuslovlennogo faktorami sredy obitanija [On the issue of establishing and evidence of harm to public health in identifying unacceptable risk due to environmental factors]. Analiz riska zdorov'ju, 2013, no. 2, pp. 14-25.

4. Kljuev N.A., Brodskij E.S. Sovremennye metody mass-spektrometricheskogo analiza organicheskih soedinenij. Rossijskij Himicheskij Zhurnal [Modern methods of mass spectrometry analysis of organic compounds]. Zhurnal Rossijskogo Himicheskogo Obshhestva im. D.I. Mendeleeva, 2002, vol. XLVI, no. 4, pp. 57-63.

5. Onuchak L.A., Arutjunov Ju.I., Zhosan A.I., Dmitrieva E.V., Aleksandrova S.V. Kolichestvennaja gazovaja hromatografija s zhidkokristallicheskim sorbentom pod dejstviem jelektricheskogo polja [Quantitative gas chromatography with a liquid crystal sorbent under the influence of an electric field]. Vestnik SamGU-Estestvennonauchnaja serija, 2009, no. 6 (72). pp. 149-158.

6. Malysheva A.G., Rahmanin Ju.A. Fiziko-himicheskie issledovanija i metody kontrolja veshhestv $\mathrm{v}$ gigiene okruzhajushhej sredy [Physical and chemical studies and methods of control of substances in environmental hygiene]. SPb.: NPO «Professional», 2012. $720 \mathrm{p}$.

7. Onishhenko G.G. Aktual'nye problemy metodologii ocenki riska i ee rol' v sovershenstvovanii sistemy social'no-gigienicheskogo monitoringa [Actual problems of risk assessment methodology and its role in improving public health monitoring]. Gigiena $i$ sanitarija, 2006, no. 5, pp. 3-7. 